\title{
The Effect of Augmented Reality on Spatial Visualization Ability of Elementary School Student
}

\author{
Danakorn Nincarean A/L Eh Phon ${ }^{\#}$, Mohd Hishamuddin Abdul Rahman*, Nur Ichsan Utama ${ }^{+}$, Mohamad \\ Bilal Ali^, Noor Dayana Abd Halim^, Shahreen Kasim ${ }^{\$}$ \\ ${ }^{\#}$ Faculty of Computer Systems \& Software Engineering, Universiti Malaysia Pahang, Pahang, Malaysia \\ E-mail:danakorn@ump.edu.my \\ *Faculty of Art, Computing, and Creative Industry, Universiti Pendidikan Sultan Idris, Tanjung Malim, Malaysia \\ mhishamuddin@fskik.upsi.edu.my \\ ${ }^{+}$School of Industrial Engineering, Telkom University, 40257 Bandung, West Java, Indonesia \\ Faculty of Education, Universiti Teknologi Malaysia, Skudai, Malaysia \\ E-mail:mba@utm.my;noordayana@utm.my
}

${ }^{\$}$ Soft Computing and Data Mining Centre, Faculty of Computer Science and Information Technology, Universiti Tun Hussein Onn, Johor, Malaysia

\begin{abstract}
The invention of Augmented Reality (AR) has provided a platform for individuals to see virtual and real objects simultaneously in a real-life setting. As compared to other technologies being implemented in education setting, it may contribute a new method to educate. This study investigated the possible effect of AR technology on students' spatial visualization ability. ARScience Magic Book Learning System (AR-SMB) is a learning tool based on the AR technology which was developed in this study to facilitate students in learning science concept, hence enhancing their spatial visualization ability. The type of data collection methodology used is the quantitative approach in which pre-test and post-test design were implemented and the participant comprised of 34 fifth-grade students. According to the results, it was found that the scores of the Mental Rotation Test (MRT) posttest were significantly greater than the pre-test, thus AR technology can be considered to be beneficial in enhancing students' spatial visualization ability. There is a huge difference in terms of the scores of MRT between the pre-test and post-test which concludes that the treatment given can significantly improve and contribute towards their spatial visualization ability. The findings of this research enable the educators to incorporate AR learning into their teaching process in order for students to understand the rotation and transformation of objects that are related to each other. As a result, this study has shown a significant implication for the understanding of AR's effect in enhancing spatial visualization ability among primary school students.
\end{abstract}

Keywords - augmented reality; computer-based education; spatial visualization ability; science education.

\section{INTRODUCTION}

Spatial visualization ability is the underlying foundation in many scientific areas. Based on many studies associated with spatial visualization ability, it is determined that the achievement of Science, Technology, Engineering, and Mathematics (STEM) is greatly influenced by spatial visualization ability [1]. Nonetheless, among many cognitive abilities, less focus has been given on this ability in the field of education [2]. Hence, numerous science educators have often overlooked this matter [3], [4]. As a result, this ability is often failed to be produced among students leading to poor results and retention problems [5]. Numerous studies have shown that there is a positive correlation between spatial visualization ability and learning performance in science [6]. Despite that, many students are still facing difficulties in understanding the basic concept of science, as many of the concepts require students to think three-dimensionally. Therefore, it is necessary to develop an effective tool to cater to students' need to have strong imagination ability because students nowadays cannot develop these spatial abilities by just learning in a traditional instruction environment. Therefore, to help students to build their spatial visualization ability, the possible solution is to instill students with a better mental rotation and transformation-thinking tool so that students can view things from various perspectives and 
their effective thinking in three dimensions can be generated.Spatial visualization ability is commonly defined as "an individual's mental ability to generate, retain, retrieve, and transform well-structured visual images" [7]. To be more precise, spatial visualization ability is used when the recognition, manipulation, and transformation of $3 \mathrm{D}$ objects are involved. Spatial visualization ability is categorized into two big dimensions; they are spatial visualization and spatial orientation [8]. Spatial visualization refers to an individual's ability to accomplish or imagine manipulating, rotating, or inserting objects in mind without depending on the rotation speed [9]. Meanwhile, spatial orientation is defined as the ability to maintain the orientation of an object [10].

Spatial visualization ability is one of the intelligence components in human [11]. Hence, cognitive achievement among students can be affected by spatial visualization ability. It is undeniable that spatial visualization ability is very important in the education setting; many educational researchers have been putting their attention on this matter to enhance students' spatial visualization ability. Based on a few past studies, by using computer technology, it is proven that spatial visualization ability can be strengthened through practice. However, in term of the use of these tools has been limited in terms of the manipulations. At a recent time, Augmented Reality (AR) is one of the recently invented technologies that have gained the public's attention; it is believed to have a positive influence on spatial visualization ability.

Augmented Reality (AR) is a kind of technology that can put the virtual objects together such as $3 \mathrm{D}$ objects generated by the computer into the real world. Principally, AR refers to an interactive system, which meets the following three criteria: (a) the integration of real world with virtual information; (b) interaction with virtual objects at a real time; and (c) users' experience in three dimensions [12]. AR is an innovative technology that able to supplement a real-world environment with a computer to generated sensory inputs. These virtual component seem to coexist with the real one in the same spaces, enhances the user perception of reality and enriching the information. AR has been touted as one of the most attractive technologies for education, is a powerful and motivating tool, which involve a combination of sound, sight, and touch [13]. For the generation that raised in interactive technologies, bringing AR technology into a classroom is effective in maintaining a high level of motivation and engagement among student [14]. The application of AR has a great potential in teaching and learning process, which has been explored currently. However, by looking at the narrow scope of the studies, only a few of them are related to the application of AR to improve spatial visualization ability.

Several works related to AR and spatial visualization ability. As discussed in [15], in order to find out whether AR technology can be used to increase spatial visualization ability, a 3D construction tool named Construct3D using a collaborative setup with a stereoscopic head-mounted display (HMD) was developed. Some 215 high school students were tested with this application. The test was taken in the form of pre-test, training, and post-test design. According to the results, there was no clear evidence to show that AR can enhance spatial visualization ability. From the inspiration of the Lego game, 3DAR-LEG game was created to boost spatial visualization ability. However, this game incorporated two methods, namely the tangible input method by utilizing a pattern marker and the traditional method such as using a keyboard or mouse [16]. The game has several levels for users to train different spatial visualization ability skills. A study was conducted with 63 participants to determine whether the game could successfully enhance spatial abilities. As a result, the average score was 6.8 out of 7 . Unfortunately, this game did not have the feature to discover at which level of spatial visualization ability the users are after the game was played.

In a vocational school, 36 students from the third-year level were taught using the AR model and tangible model to build their spatial visualization ability [17]. As a result of the study, a tangible model was significantly more effective in improving their abilities to transform 3D objects into 2D projections. However, it was found that there was no standard spatial visualization ability test being used to find out the effectiveness of the two models in terms of spatial visualization ability improvement. On the other hand, a similar study was conducted on first-year engineering students. Based on the study, the content of the AR was comprised of a series of exercise in an organization of difficulty from low to high. It was found that learning through AR could positively improve spatial visualization ability [18].

The use of Augmented Reality (AR) in an educational setting has been receiving substantial attention from educational researchers [19]. The learning experience is important in teaching and learning process for primary education due to student need to gain more attention to increase motivation and satisfaction in the classroom. Spatial concepts can be represented by the uniqueness of AR in putting virtual objects into the real world, and at the same time, it can create an enthusiasm feeling among learners [18]. Despite this, there have been only a small number of studies focused on the use of AR in learning process [20] and most of the studies only emphasized students from higher education setting [21]. Hence, this study aims to construct a learning tool based on AR technology for science learning and study the influence of AR towards the spatial visualization ability of elementary school students.

\section{MATERIAL AND METHOD}

\section{A. Research Design}

A quantitative method with a pre-experimental design of one group pre-test and post-test design was used to reach the objective of this study.

\section{B. Sample}

Thirty-four of fifth-grade students (10 years old) from one of the primary schools in East Malaysia were selected as the sample of the study. The reason for these samples being selected is that they just started to learn science theory specifically on astronomy, which requires a strong spatial visualization ability.

\section{AR-Science Magic Book Learning System}

AR-Science Magic Book Learning System (AR-SMB) is a learning tool based on the AR technology, which was 
created to facilitate students in learning and overtaking misconceptions about science concepts. Based on the module, the content was made by the syllabus of fifth-grade elementary science, which was specified on the astronomy topic.

In the application of AR-SMB, recognition of pages in the book can be made by using a webcam and then turning them into 3D presentations. Only a few necessary types of equipment are required to run this system such as webcam, marker, and laptop or desktop. To represent the virtual objects in every page of AR-SMB, a few items are needed such as notes, diagrams, and pattern markers. Below the notes section, there will be instruction given to facilitate users on choosing which marker to use. After starting the system, the students can make exploration and manipulation towards the pattern markers to illustrate virtual objects in order for them to understand the content better. They can see the 'real' earth, moon and sun which are represented by 3D effects. When a webcam detects a marker on a book, the AR software will create a virtual object, which can be manipulated by rotating or tilting the marker pattern or book (Refer Fig. 1-4).

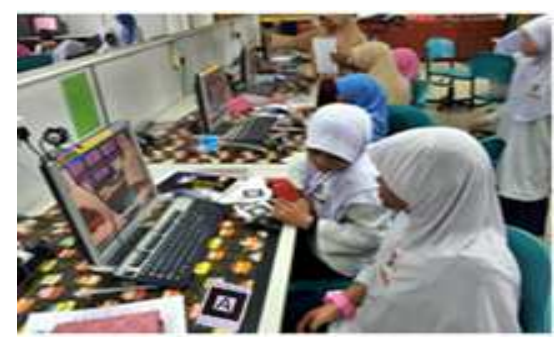

Fig. 1.Students are collaborating during AR activity

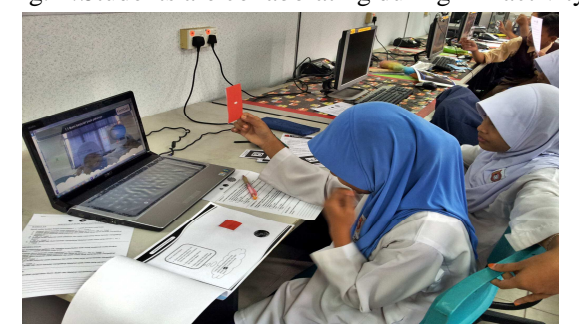

Fig. 2. Students' interaction with the AR.

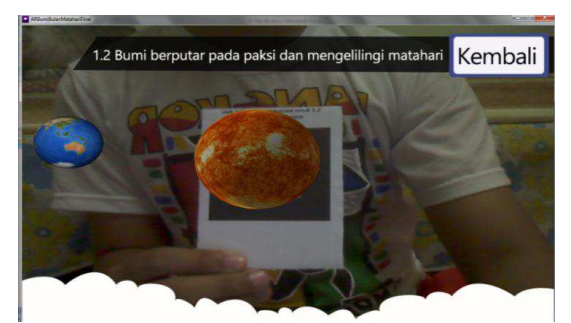

Fig. 3. 3D models of first AR activity

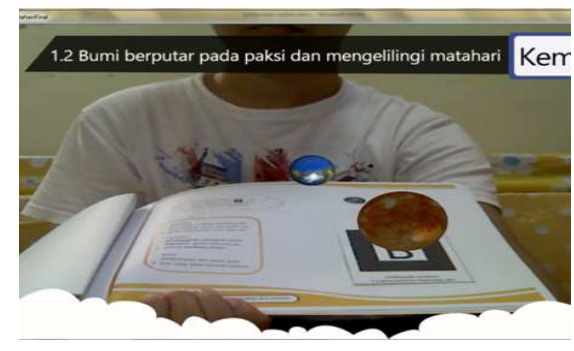

Fig. 4. 3D animation pops up from the AR books

\section{Instrument}

In this experiment, we adopted one instrument in order to achieve the goal of the study. A test named the Mental Rotation Test (MRT) was used to collect the data by measuring the participants' spatial visualization ability [22]. This test is one of the common tools used by researchers to conduct spatial visualization ability assessment. There are 20 items in MRT, and the total score of MRT is 20 points. In each item, there are two sides; the left side consists of a target figure and the right side consists of four sample stimuli. The participant needs to choose the correct figure that represents the rotation of the target figure. Some adaptations or modifications were made on the items to prevent students from being affected by the floor effect [23]. The alternative figures were reduced to three instead of maintaining at four. Based on many past studies, it was claimed that the reliability of the test was .88 , meaning that the consistency and reliability of this test were at the satisfaction level. Meanwhile, the Cronbach's alpha of this study was .86. Fig. 5 shows examples of MRT items.

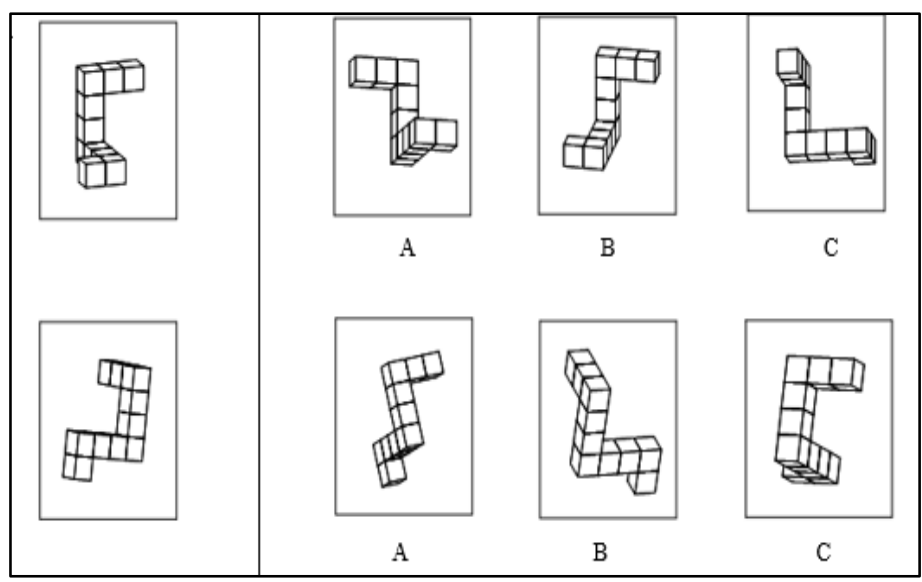

Fig. 5.A sample of the items in the MRT test

\section{E. Procedure}

The setting of the study is in a laboratory of the selected primary school. The laboratory is equipped with a webcam, computer, and AR-SMB. There were a few steps in conducting the study, which is shown in Fig. 3. In Week 1, the spatial visualization ability of each student was accessed by asking him or her to sit for the MRT. In this phase, they need to gather and answer the MRT pre-test for 10 minutes. In Week 2, brief training was conducted on students to show them how to control AR to avoid improper use and confusion. In training, there were two pattern markers; an instruction sheet was provided to guide them to use the pattern markers and AR interface. In Week 3, the students were required to make exploration and work on the task using the AR-SMB provided.

This activity was constructed to facilitate students with the learning process and enable them to make more interaction with the system where they had the opportunity to make discussion, think and draw a conclusion based on the given questions by referring to AR. The students were free to make manipulation on the pattern markers without any restriction so that they can understand the concepts. In the experiment, they were asked to learn how the Earth, the 
moon, and the sun move. Five pattern markers represented five animations of virtual objects.

In the following week, which is Week 4, they learned about the occurrence of day and night by using the pattern markers from the AR-SMB to represent the sun and the Earth models. Two pattern markers were used in this module to represent the concept of the phenomenon of day and night. In Week 5, they learned about the phases of the moon where there are eight major phases that the moon goes through. In this module, one pattern marker to represent the moon and 8 slots of spaces provided to show each phase of the moon. After the treatment was completely given, the students sat for the MRT post-test to evaluate their spatial visualization ability. The post-test of MRT was similar to pre-test but in a different order. The purpose of this phase is to access the spatial visualization ability of the student after they are gone through three activities with AR. Fig. 6 shows the data collection procedures for the entire six weeks.

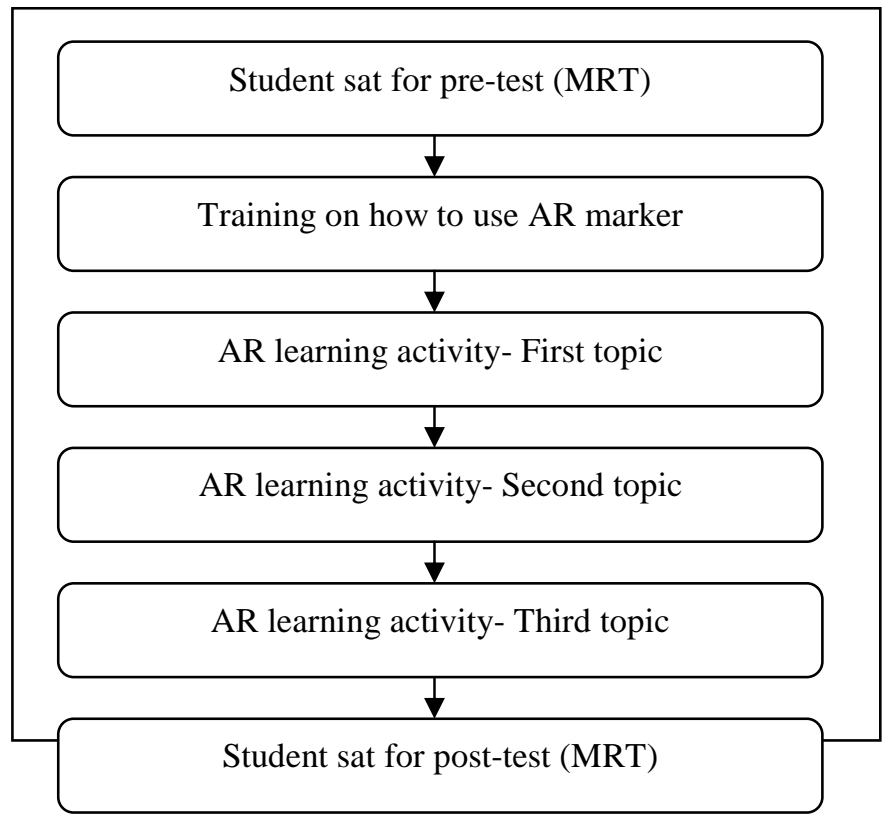

Fig. 6. The methodology of the study

\section{RESULTS AND DISCUSSION}

There were 34 participants participated in this study. Before the treatment, they sat for pre MRT test to access their prior level of spatial visualization ability. After that, the treatment using AR, which consists of three modules, was given to the students. After the treatment, the students were given a post-test to access their spatial visualization ability after the AR treatment. Table I illustrates the descriptive statistics of the MRT pre-test and post-test obtained by the students and Fig. 4 shows a general review of the comparison between the students' results for their pre-test and post-test scores of MRT test.

TABLE I

DIFFERENCE BETWEEN THE MEAN AND STANDARD DEVIATION

\begin{tabular}{|l|c|c|c|}
\hline MRT & N & Mean & $\begin{array}{c}\text { Standard } \\
\text { Deviation }\end{array}$ \\
\hline Pre-test (MRT) & 34 & 8.26 & 2.821 \\
\hline Post-test (MRT) & 34 & 15.50 & 2.019 \\
\hline
\end{tabular}

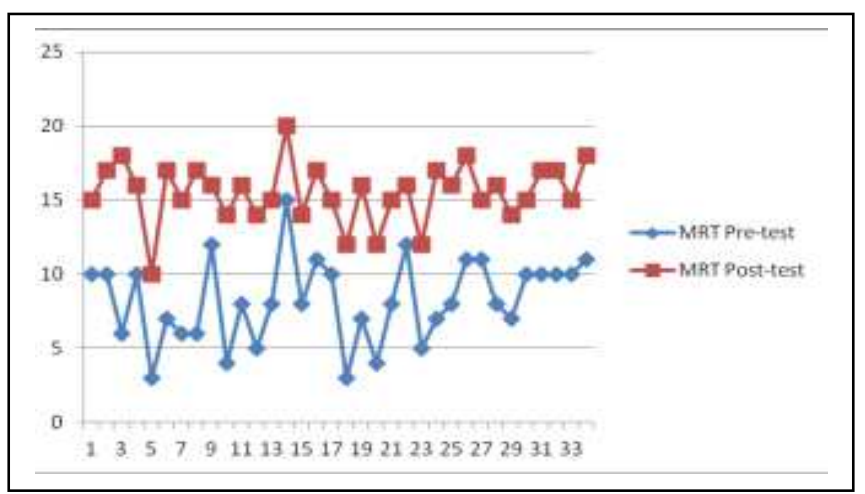

Fig. 7. Comparison of student's MRT pretest and posttest.

As shown in Table 1, there is a difference between the mean and standard deviation for both of the test. The mean and standard deviation for MRT pre-test was 8.26 and 2.821 respectively. Meanwhile, for post-test, the mean and standard deviation was 15.50 and 2.109. It shows that there is a difference between the students' pre-test scores and post-test scores.

To achieve the purpose of this study, which is to examine the potential of AR towards the spatial visualization ability of the students, the researchers performed a paired-samples t-test utilizing SPSS at a 0.05 confidence level.

TABLE II

Descriptive Statistic Of Student Mrt Test

\begin{tabular}{|c|c|c|c|c|c|c|c|c|}
\hline & \multicolumn{5}{|c|}{ Pair differences } & \multirow[t]{3}{*}{$t$} & \multirow[t]{3}{*}{$d f$} & \multirow{3}{*}{$\begin{array}{c}\text { Sig. } \\
(2- \\
\text { tailed })\end{array}$} \\
\hline & \multirow[t]{2}{*}{ Mean } & \multirow[t]{2}{*}{ Std Deviation } & \multirow[t]{2}{*}{ Std Error Mean } & \multicolumn{2}{|c|}{$\begin{array}{l}95 \% \text { Confidence Interval } \\
\text { of the Difference }\end{array}$} & & & \\
\hline & & & & Lower & Upper & & & \\
\hline $\begin{array}{l}\text { MRT Posttest- MRT pre- } \\
\text { test score }\end{array}$ & -7.235 & 2.031 & .348 & -7.944 & -6.527 & -20.773 & 33 & .000 \\
\hline
\end{tabular}

From Table II, the results of a paired or correlated sample t-test indicated that the AR was found significantly influence the spatial visualization ability in the MRT test $(t=-20.8, p-$ value $=.000)$. Based on the results, it is undeniable that there is a significant difference between the score of the pre-test and post-test. Their spatial visualization ability has been 
greatly improved after the treatment was given. Hence, it can be concluded that the use of AR-SMB has significantly enhanced its spatial visualization ability.

This study was conducted to find out whether the application of AR can benefit the students in terms of spatial visualization ability. The current study has proven that the enhancement of this ability can be facilitated using AR. After the pre-test and post-test were applied, it is obvious that the scores of the post-test are significantly higher. To be more specific, the students are now able to think, imagine, and view from the various point of view after they received the treatment of AR-SMB in this study. The result is consistent with data acquired in [24]-[26], which have proven that the AR technology could contribute to enhancing spatial visualization ability. Spatial visualization ability can be definite as an ability used by individuals to visualize the configuration of an object if it is folded, rotated, relocated or transformed; all these orientations can be facilitated by AR technology. This is because AR provides a platform for students to manipulate a virtual object freely from various perspectives as they can use their bare hands to make manipulation [27]. This activity allows them to use their prerequisite knowledge regarding the real world setting to make interaction with the learning content. They can simply move around and tilt the AR marker to freely adjust perspectives and move nearer and farther to adjust the scale of the virtual objects.

Also, each learning task conducted in this study required the students to observe and manipulate the virtual objects in order for them to understand and manage to answer the question. Every time they have a problem in understanding the task given, they can view the virtual object projected by the AR system. AR provided the ability to help students develop a deeper understanding of the concept of Earth and the universe that requires them to observe the events that occur from a variety of perspectives by using AR. Such a process is similar to the process performed by students in solving problems in the MRT tests, which required spatial visualization ability.

Besides that, another clarification for these findings also due to AR comprises of representation that can be modeled in $3 \mathrm{D}$, which in turn can affect spatial visualization abilities. Virtual objects are produced with AR, which can be seen three-dimensionally; thus, students do not need to burden themselves with heavy working memory load as the spatial information process is reduced. The content of science topics especially astronomy is usually quite abstract, and it needs high spatial visualization ability to understand.

With the use of 3D imagery, students can visualize the abstract concept, which cannot be easily seen in a real-life setting. Hence, there is no need for students to apply spatial processing schema to transform $2 \mathrm{D}$ objects into $3 \mathrm{D}$ objects because AR can improve their spatial abilities.

Research also proved that the learning material used for teaching and learning play an important role and affecting spatial visualization ability. The main problem with the current method to improve the learning environment that requires spatial visualization ability is the use of $2 \mathrm{D}$ materials. Therefore, it is important to incorporate the $3 \mathrm{D}$ technology-based education into the teaching and learning process. With enhancement in education, traditional ways of education are not efficient. The process of teaching and learning in primary school is used a conventional method such as using chalk to write, textbook and graphic to explain [28]. Textbook play a traditional role in the science classroom. Teachers used a textbook only to help the student read the topic being taught. However, textbook reading only is not enough to encourage students to learn well. Students need to imagine himself/herself a real-world environment of the chapter they studying. A study revealed that many children disagree with the methods of teaching that only focused on the textbook only. It was found that many teachers focused on memorizing rather than making a student understand [29]. Teacher not only needs to find the research-based problems suitable for their classes but also need pedagogical support to implement the problems. The most student could remember and retain the knowledge in the topic that was taught using AR application [30]. Since spatial visualization ability is the ability that used to rotate and manipulate three-dimensional (3D) objects in an imaginative space, so the incorporation of AR, which is mainly based on the $3 \mathrm{D}$ representation of visual and allow the interaction from a different perspective was one of the teaching tools that.

\section{CONCLUSION}

The goal of this study is to find out the impact of learning through AR towards the spatial visualization ability of the students. It was found that AR technology has a positive effect on improving students' spatial visualization ability. There is a huge difference in terms of the scores of MRT between the pre-test and post-test which concludes that the treatment given can significantly improve and contribute towards their spatial visualization ability. The findings of this research enable the educators to incorporate AR learning into their teaching process in order for students to understand the rotation and transformation of objects that are related to each other. The ability to combine virtual objects and the real environment makes $\mathrm{AR}$ unique, and it is unachievable with the use of other technologies. However, this study has its limitation in which there was no presence of a control group. Therefore, the improvement of the posttest score of students may not only due to the AR learning experiment, but it could also be affected by other variables. It is recommended to have a control group in the future investigation. In future development, this research could be enhanced by referring to various other works available such as in [31], [32]. Concisely, it can be said that AR technology is beneficial in helping students to develop and improve spatial visualization ability and it can be implemented in the teaching and learning process effectively.

\section{ACKNOWLEDGMENT}

The authors would like to thank the Universiti Malaysia Pahang (UMP) for the support in making this project possible. This work was supported by RDU Grant Vot No. RDU180361 initiated by UMP. We would also like to thank the Universiti Tun Hussein Onn for supporting this research under the Contract Grant Vot number W004. 


\section{REFERENCES}

[1] D. Reilly, D. L. Neumann \& G. Andrews, "Gender differences in spatial visualization ability: Implications for STEM education and approaches to reducing the gender gap for parents and educators. In Visual-spatial visualization ability in STEM Education (pp. 195-224). Springer, Cham, 2017

[2] C. L. Gohm, L. G. Humphreys, and G. Yao, "Underachievement among spatially gifted students." American Educational Research Journal, 35(3), 515-531, 1998.

[3] M. Hegarty, "Spatial thinking in undergraduate science education." Spatial Cognition \& Computation, 14(2), 142-167, 2014.

J. Buckley, N. Seery, \& D. Canty, "A heuristic framework of spatial visualization ability: A review and synthesis of spatial factor literature to support its translation into STEM education." Educational Psychology Review, 1-26, 2018.

[4] S. Sorby, E. Nevin, A. Behan, E. Mageean, E., and S. Sheridan, "Spatial skills as predictors of success in first-year engineering." IEEE In Frontiers in Education Conference (FIE), pp. 1-7, October 2014. IEEE

[5] J. F. Johnson, L. G. Barron, M. R. Rose, \& T. R. Carretta, "Validity of Spatial visualization ability Tests for Selection into STEM (Science, Technology, Engineering, and Math) Career Fields: The Example of Military Aviation." In Visual-spatial visualization ability in STEM Education, (pp. 11-34). Springer, Cham, 2017.

[6] D. F. Lohman, "Spatial visualization ability and G. In I. Dennis \& P. Tapsfield (Eds.), Human abilities: their nature and measurementHillsdale, NJ: Erlbaum, 1996, pp. 97 -116.

[7] G. M.Bodner and R. B. Guay, "The Purdue visualization of rotation test." The Chemical Educator, 2 (4), 1-17, 1997.

[8] H. B. Yilmaz, "On the development and measurement of spatial visualization ability." International Electronic Journal of Elementary Education, 1(2), 83-96, 2017.

[9] E. D. Ragan, S. Scerbo, F. Bacim \& D. A. Bowman, "Amplified head rotation in virtual reality and the effects on $3 \mathrm{~d}$ search, training transfer, and spatial orientation". IEEE transactions on visualization and computer graphics, 23(8), 1880-1895, 2017

[10] C. Roca-González, J. Martin-Gutierrez, M. GarcÍa-Dominguez, M., \& del Carmen Mato Carrodeguas, "Virtual Technologies to Develop Visual-Spatial visualization ability in Engineering Students." Eurasia Journal of Mathematics, Science \& Technology Education, 13(2), 2017

[11] R. T. Azuma, "A survey of augmented reality," PresenceTeleoperators and Virtual Environments, 6 (4), 355 - 385, 1997.

[12] M. Contero, J. M., Gomis, F. Naya, F., Albert, and Martin-Gutierrez, J. (2012, October). Development of augmented reality-based remedial course to improve the spatial visualization ability of engineering students. In Frontiers in Education Conference (FIE), 2012 (pp. 1-5). IEEE.

[13] A. Cascales, I. Laguna, D. Pérez-López, P. Perona, \& M. Contero, "Augmented Reality for preschoolers: An experience around Natural Sciences educational contents". Spdece, (June), 113-122, 2012.

[14] M. B. Ibáñez, \& Delgado-Kloos, C. "Augmented reality for STEM learning: A systematic review." Computers \& Education, 2018.

[15] A. Dünser, K. Steinbügl, H. Kaufmann, and J. Glück, (2006, July). Virtual and augmented reality as spatial visualization ability training tools. In Proceedings of the 7th ACM SIGCHI New Zealand chapter's international conference on Computer-human interaction: design centered HCI (pp. 125-132). ACM.

[16] T. Do, J. W. Lee. and J. Jacko, "A Multiple-Level 3D-LEGO Game in Augmented Reality for Improving Spatial visualization ability". Human-Computer Interaction. Interacting in Various Application
Domains. Lecture Notes in Computer Science. 5613, pp. 296-303, 2009.

[17] Y. C. Chen, HL. Chi, W. H. Hung and S. C Kang, "Use of Tangible and Augmented Reality Models in Engineering Graphics Courses." Journal of Professional Issues in Engineering Education and Practice. 137(4), pp. 267-276, 2011.

[18] K. H. Cheng, "Reading an augmented reality book: An exploration of learners' cognitive load, motivation, and attitudes." Australasian Journal of Educational Technology, 33(4), 2017

[19] J. Holopainen, O. Mattila, P. Parvinen, E. Pöyry, \& K. Seppälä, "Employing Mixed Reality Applications: Customer Experience Perspective." In Proceedings of the 51st Hawaii International Conference on System Sciences, 2018.

[20] E. T. Gün, \& B. Atasoy, "The Effects of Augmented Reality on Elementary School Students' Spatial visualization ability and Academic Achievement." Egitim ve Bilim, 42(191), 2017.

[21] J. Bacca, S. Baldiris, R. Fabregat, S. Graf, and Kinshuk, "Augmented reality trends in education: a systematic review of research and applications." Educational Technology \& Society, 17(4), 133-149, 2014.

[22] M. Peters, B. Laeng, K. Latham, M. Jackson, R. Zaiyouna, C. Richardson. "A redrawn Vandenberg and Kuse mental rotations test - different versions and factors that affect performance." Brain and Cognition, 28(1), 39-58, 1995.

[23] L. Verderhus and S. Krekling, "Sex Differences in Visual-Spatial visualization ability in 9-Year-Old Children". Intelligence, 23, 33-43, 1996.

[24] C. Carbonell Carrera, \& L. A., Bermejo Asensio, "Augmented reality as a digital teaching environment to develop spatial thinking." Cartography and geographic information science, 44(3), 259-270, 2017.

[25] Z. Y. Hoe, I. J. Lee, C. H. Chen, \& K. P. Chang, "Using an augmented reality-based training system to promote spatial visualization ability for the elderly." Universal Access in the Information Society, 1-16, 2017.

[26] J. Martin-Gutierrez, J. L. Saorin, M. Contero, M. Alcaniz, M., D. C. Perez-Lopez, and M. Ortega, "Design and validation of an augmented book for spatial abilities development in engineering students. Computers \& Graphics, 34 (1), 77-91, 2010

[27] D. N. E. Phon, M. B. Ali, and N. D. A. Halim, "Learning with Augmented Reality: Effects Toward Student with Different Spatial Abilities."Advanced Science Letters, 21(7), 2200-2204, 2015.

[28] N. M. B. Izwan, Z. S. I. Syed and A. R. Salleh, "The Use of Augmented Reality Technology for Primary School Education in Perlis, Malaysia." IOP Conf. Series: Journal of Physics: Conf. Series 1019, 2018

[29] M. Rasmy, S. Selvadurai, and J. Sulehan, "Social Environmental Determinants of Student Dropout in the Plantation Settlement. Malaysian Journal of Society and Spac, 13(2), 54-64, 2017.

[30] S.C Chang and G. J. Hwang, "Impacts of an augmented reality-based flipped learning guiding approach on students' scientific project performance and perceptions. Computers \& Education, 2018

[31] M.A. Ismail, V. Mezhuyev, K. Moorthy, S. Kasim, A.O. Ibrahim, "Optimisation of Biochemical Systems Production using Hybrid of Newton Method, Differential Evolution Algorithm and Cooperative Coevolution Algorithm," Indonesian Journal of Electrical Engineering and Computer Science, vol.8, pp. 27-35, 2017.

[32] M.A. Ismail, V. Mezhuyev, S. Deris, M.S. Mohamad, S. Kasim, R.R Saedudin, "Multi-objective Optimization of Biochemical System Production Using an Improve Newton Competitive Differential Evolution Method," International Journal on Advanced Science, Engineering and Information Technology, vol.7, pp.1535-1542, 2017 